\title{
EN BUSCA DE KLINGSOR O EL RELATO IMPOSIBLE
}

\author{
En busca de Klingsor or the impossible narrative
}

\author{
Juan Pablo Morales Trigueros \\ Universidad de Costa Rica, Costa Rica \\ jppmorales@gmail.com
}

Recibido: 11-05-2018

Aprobado: 28-05-2018

\begin{abstract}
Juan Pablo Morales Trigueros es Mágister en Literatura Latinoamericana por la Universidad de Costa Rica. Actualmente labora como profesor en la Escuela de Estudios Generales de la Universidad de Costa Rica.
\end{abstract}

\section{RESUMEN}

El presente artículo explora los procedimientos enunciativos que En busca de Klingsor, de Jorge Volpi, utiliza para crear una entidad narradora falible a partir de la cual se comentan tanto el hecho mismo de la narración literaria como el de la autenticidad de discursos tan pretendidamente objetivos como el histórico y el científico. A partir de la relación tanto con los recursos de los diarios de viaje como de la novela policial, se estudia el mecanismo escritural que permite este cuestionamiento del narrador y lo que significa su falibilidad para el proceso de lectura.

Palabras clave: narrativa; ciencia; objetividad; ciencia fusión

\begin{abstract}
This work explores the enunciative procedures used in En busca de Klingsor, by Jorge Volpi, in order to create a fallible narrator entity from which both actual literary storytelling and the authenticity of so called objective discourses, like science and history are commented. Parting from the relation with resources from both travel diaries and police novels, the paper studies the writing mechanics which allows the questioning of the narrator and what its fallibility means to the reading process.
\end{abstract}

Keywords: narrative; sciencie; objectivity; fusion science

"Aunque mi trabajo no es estrictamente científico, profesor (...), trato de aplicar los mismos principios de la ciencia".

Jorge Volpi, En busca de Klingsor, libro segundo 


\section{Introducción}

En 1999, la editorial Seix Barral retomó la tradición de otorgar el Premio Biblioteca Breve, la cual se había interrumpido en 1972. El galardonado fue Jorge Volpi, un escritor mexicano muy poco conocido hasta entonces, que acaparó la atención del jurado con su novela En busca de Klingsor, la cual Guillermo Cabrera Infante calificó de "ejemplar del arte que quiero llamar la ciencia-fusión. Fusión de la ciencia con la historia, la política y la literatura para conformar eso que llamamos cultura". En efecto, el texto realiza una interesante fusión de historia, ciencia y ficción, no solo a nivel de contenido sino también de forma, por la manera en que están presentados los apartados y la forma no lineal en que se cuenta la trama. En este trabajo analizaré el proceso mediante el cual el narrador de la novela busca la verosimilitud ante el lector, para lo que tomaré en cuenta nociones como la mímesis, la verosimilitud y la instancia del narrador como tal, además de algunos rasgos de la novela policial y su correspondencia con el método científico moderno.

\section{Mentira, verdad y ficción}

En busca de Klingsor es una novela. No falta confirmación institucional dado el premio que se le otorgó y, por si tras su lectura quedara alguna duda, el mismo Volpi incluye una "Nota final", al principio de la cual se lee "ésta es una obra de ficción" (1999, p. 441). Si considero la posibilidad de que quede duda es porque la sola existencia de dicha nota puede considerarse muestra de temor ante una posible malinterpretación del texto. La razón puede rastrearse en la primera parte de la novela, en la que el narrador afirma

\footnotetext{
... debo aclarar que yo -una persona de carne y hueso, idéntica a ustedes- soy el autor de estas páginas. ¿Y quién soy yo? Como se habrán dado cuenta al mirar la cubierta de este libro -si es que algún editor se ha tomado la molestia de publicarlo-, mi nombre es Gustav Links (1999, pp. 23-24).
}

Claro, cualquiera que sintiera curiosidad y consultara la cubierta del libro se encontraría el nombre de Jorge Volpi en ella, desmintiendo lo dicho en la cita. La aclaración final del autor se lee como un último intento por desalojar, definitivamente, la posibilidad de que alguien considere que lo leído es la transcripción de un documento redactado por un tal (y real) Gustav Links. Ciertamente hay un juego con la entidad no solo del narrador, sino del propio 
autor, en tanto se va más allá de ceder la voz narrativa, gestando una suerte de "ruptura de cuarta pared" a través de la mención que el narrador hace de la cubierta del libro. Más que ocuparse de enunciar la historia, el narrador "invade" la realidad física del libro mencionando su portada, aunque esta no es la misma portada que cubre el libro en que se da tal mención. Se trata de un recurso estético basado en ese juego entre autor y narrador, que empezó a gestarse en el fragmento citado.

Poco probable es que alguien haya interrumpido ahí su lectura sintiéndose estafado $u$ ofendido por la incongruencia entre lo dicho en el texto y la realidad física del libro que lo contiene. La razón se encuentra en lo que Darío Villanueva la define como "Pacto narrativo":

Contrato implícito que se establece entre el EMISOR de un mensaje narrativo y cada uno de sus RECEPTORES, mediante el cual éstos aceptan determinadas normas para una cabal comprensión del mismo, por ejemplo la de la FICCIONALIDAD de lo que se les va a contar, es decir, la renuncia a las pruebas de verificación de lo narrado y al principio de sinceridad por parte del que narra (Villanueva, 1989).

El contrato entre narrador y lector lleva a este último a creer lo que aquel le cuente, proceso que suele ocurrir salvo situaciones especialísimas (la psicosis y la infancia, tal vez). De modo que a pesar de encontrarnos ante una mentira, que Gustav Links es el autor de lo que leemos, seguimos adelante con la excusa de que al narrador se le cree. Ahora bien, la afirmación de la autoría aparece en el primer apartado del "Libro Primero" de la novela, el cual se titula "Leyes del movimiento narrativo". Dichas leyes ("Toda narración ha sido escrita por un narrador" (p. 23), "Todo narrador ofrece una verdad única" (p. 24) y "Todo narrador tiene un motivo para narrar" (p. 25)) son enunciadas por Links con un correspondiente "Corolario" en que se las comenta. A resumidas cuentas: la narración es suya, lo que narra se trata de su verdad y si la narra es porque tiene un motivo. Ya desde aquí hay una suerte de pretensión de veracidad por parte del narrador: su texto, aunque enuncie una verdad personal, enuncia una verdad, algo que es cierto. No existiría dificultad, o mínima resistencia, ante una narración en primera persona en la que se contaran situaciones protagonizadas por el narrador. No obstante, lo primero que hace Links tras la propuesta y argumentación de sus leyes narrativas es contarnos cómo el teniente Francis $P$. Bacon llegó a Núremberg en 1946 para investigar ciertas "discordancias" en los testimonios de los crímenes de guerra con respecto a la investigación científica nazi. Más aún, tras este episodio, Links pasa a narrar la infancia y primera juventud de Bacon con gran lujo de detalles, incluidos episodios familiares y de sus años de estudiante. Este apartado se titula "Hipótesis: de la física cuántica al 
espionaje" y está dividido en cinco secciones (hipótesis), una por cada episodio de la vida de Bacon que describe. Lo interesante viene una vez finalizadas las hipótesis, cuando la novela pasa al apartado llamado "Breve disquisición autobiográfica: de la teoría de conjuntos al totalitarismo", en el cual Links explica la razón de ser del título del apartado anterior:

Un hombre de ciencia como yo, sabe que, sin pruebas, cualquier teoría se desmorona en el aire. He aquí mi réplica: no puedo decir que todos los hechos que he descrito sean verdaderos - de ahí que los haya denominado hipótesis-, pues lo cierto es que no me tocó presenciarlos (p. 111, cursiva en el original).

Si conoce la vida de Bacon, es porque este se la contó en determinado momento y lo que leemos es la reorganización que Links realiza de esos recuerdos. Lo curioso es que aunque entre narrador y lector medie el contrato narrativo ya descrito, aquel se empeñe en señalar su propia falibilidad con respecto a la exactitud de la historia que cuenta. Él la vivió, sí, pero no en su totalidad, por lo tanto, sobre ciertos acontecimientos lo único que le queda es hacer hipótesis.

Al respecto de la verosimilitud en literatura, señala Kurt Spang:

toda creación literaria es en mayor o menor grado una remodelación de la realidad. Toda creación literaria implica necesariamente la plasmación más o menos libre de una realidad humana y material, que no es -salvo en contadas excepciones- servil reproducción de una realidad existente. El problema es, si esto es mentira o no (Spang, 1984).

Sobre todo en una novela como En busca de Klingsor, dada la fusión de elementos históricos y ficcionales, es notoria la remodelación de la realidad que se lleva a cabo. El "problema" apuntado por Spang no se remite a la realidad extratextual, sino a la misma consistencia del texto y su capacidad de convencer o no a quien lo lee. Vale analizar la propuesta de Links y considerar las posibles motivaciones tras ella.

El "Prefacio" de la novela aparece firmado por "Prof. Gustav Links. Matemático de la Universidad de Leipzig" (p. 19). Es la primera caracterización del narrador que ofrece el texto, indicando su profesión y afiliación institucional. Su procedencia justifica la inclinación a la cientificidad y objetividad de su narración, la cual motivaría la cura en salud que Links realiza con la propuesta de las hipótesis. No obstante, esta sinceridad del narrador lleva a una paradoja importante: siendo Links ficcional, al igual que Bacon (hecho irrelevante para la verosimilitud y coherencia novelística), la única fuente de su historia es la 
narración que él mismo enuncia, no existe otra con la cual corroborar los hechos, por lo que la falibilidad del narrador nos deja en problemas: si la única fuente no es infalible, ¿qué lo es? No obstante, lo interesate no es tanto señalar esa falibilidad pues, estrictamente, podría decirse que todo texto narrativo está enunciado desde una subjetividad falible (aún en los que figura un narrador omnisciente, pues este también decide qué contar y qué no); lo importante es que, poco ortodoxamente, este narrador evidencia su propia falibilidad. Como se verá a continuación, el hecho no es gratuito.

\title{
2. Cambio de paradigma
}

Links es un científico devenido escritor. Claro que, dentro del mundo narrado, su intención no es literaria, sino testimonial. No obstante, como señala Werner Mackenbach a propósito de la intención testimonial literaria,

\begin{abstract}
No son las opiniones, los criterios, los sentimientos con los que se articulan y en los que se expresan los recuerdos, las reconstrucciones, los relatos de un tiempo pasado desde un presente (aunque, por supuesto, influyen en esta conflictividad), sino la relación no armónica, conflictiva e incluso contradictoria de tres instancias: la memoria, la historia y la literatura (imaginación, ficción)(2005).
\end{abstract}

Así pues, ningún testimonio es fáctico en cuanto no puede homologarse con el hecho ocurrido. Todo intento de recrear estará permeado por la subjetividad desde donde se enuncie, lo que "en verdad pasó" es irrecuperable, solo quedan las versiones que puedan dar los implicados. Así, es viable decir que toda narrativa es ficcional, ya sea literaria, testimonial, biográfica o incluso histórica. De hecho, en el caso del texto de Links no hace falta ir muy lejos para constatarlo, ya que, de nuevo, él mismo señala que no puede dar fe de la veracidad de todo lo que narra. A la luz de la reflexión anterior, tampoco podría hacerlo de lo que él mismo presenció, pues de una forma u otra su relato estará permeado por su voluntad, por su deseo de contarlo así y no de otra manera.

Carolina Depetris, en su artículo "Del testimonio científico a la narración literaria:

El diario de expedición de Luis de la Cruz", analiza cómo un texto de supuesta precisión científica termina deviniendo en literatura. Los diarios de viaje responden a reglas muy estrictas de funcionamiento epistemológico y discursivo: básicamente, mediante la descripción, deben registrar objetiva e imparcialmente la observación realizada sobre una geografía con el fin ulterior de generar una evidencia, un saber cierto e indubitable sobre ella (2006, p. 108). 
Es la intención de toda divulgación científica: generar conocimiento exacto y comprobable. Sin embargo, Luis de la Cruz convierte su texto en algo más, dado que

en la anotación de lo observado opera (...) una doble transcripción, ya que el diarista anota lo que observa mientras lo observa, y transcribe sus apuntes de manera más organizada después (p. 110).

La conformación del texto exige un tratamiento posterior en la cual se versionará la realidad indefectiblemente. La narración

comienza a centrarse en su función poética, el relato se colma de detalles y acontecimientos inútiles para su funcionamiento epistemológico, pero imprescindibles para la generación de un determinado argumento narrativo sujeto a una determinada expectativa (p. 103).

La cohesión textual depende de esos acontecimientos inútiles pues al fin y al cabo se está escribiendo, y la escritura es una reelaboración en sí misma, sin importar la pretensión de objetividad que se maneje. El hilo narrativo o argumentativo que es necesario para sostener un texto y seguirlo, no siempre permitirá la objetividad. Como narrador, Links incurre en estas "faltas" a la objetividad, no solo en las hipótesis, sino en todo el texto, pues incluye diálogos completos y constantes juicios de valor, como cuando sentencia, respecto a la actitud de Frank con Irene, su amante: "En su caso, yo ya la hubiese dejado o por lo menos le habría impedido intervenir en mis asuntos, pero el pobre Bacon era más timorato" (1999, p. 294).

Esta afirmación, cabe mencionar, es hecha por Links mientras narra un episodio en que Irene está desconfiando de él. Sus emociones, incluso su conveniencia, se transparentan a través de la porosidad del texto. El narrador modifica lo que narra, pues no se trata más de hechos, sino de escritura. En palabras de Depetris,

el sujeto deviene objeto: ya no se trata solamente de observar el entorno sino de "verse" en ese entorno, verse a sí mismo en el escenario del viaje, verse "fuera" desde "dentro", verse en la doble posición de ser tanto sujeto como objeto para sí (...) la visión deja de ser imparcial y empieza a estar matizada por valores y juicios variables propios del sujeto y que funcionan como a priori en esta manera ya no objetiva sino específica de ver las cosas y de presentarlas. Cambia el paradigama científico y poético en el diario de Cruz, porque la ilusión de mímesis o ilusión referencial que debería operar en su escrito comienza a desplazar el acento desde la referencia hacia la fuerza ficcional de la palabra "ilusión" (2006, pp. 118-119). 
El que Links sea un narrador protagonista, dotado con claridad de nombre y procedencia, agrega complejidad por el hecho de que al narrar su historia él se narra a sí mismo, se "observa", es objeto de la misma enunciación de la que es sujeto, mira y es mirado por su propia mirada. Su historia, aún dicha con sus propias palabras, es una versión más, o, en sus términos, una hipótesis.

Por lo visto, estamos ante un juego de verosimilitud en el que se pasa revisión a la instancia del narrador, exponiendo sus falibilidades y limitaciones sin por ello lograr, ni siquiera pretender, la deslegitimación de la literatura como discurso coherente (después de todo, el texto es una novela). Ahora bien, es necesario considerar el tratamiento estético mediante el que se desarrolla la trama de En busca de Klingsor para dilucidar las posibilidades críticas y analíticas de la obra, consideración que llevará a interesantes conclusiones con respecto al juego con la verosimilitud y la instancia del narrador ya apuntada.

\section{En busca de Klingsor, ¿novela policial?}

Francis Bacon visita la Alemania de posguerra para investigar la identidad de un agente nazi quien, bajo el nombre clave de Klingsor, se encargó de asesorar a Hitler durante la guerra. En términos muy elementales podría tomarse como la trama de una novela policial. Hablando de "verdad", cabe aclarar qué tipo de verdad se busca en la literatura policial, para lo que resulta utilísima la reflexión de Fernando Morales sobre la propuesta metodológica de Francis Bacon, el filósofo inglés con el que el protagonista de la novela comparte nombre y apellido:

\footnotetext{
Dejando de lado el método deductivo y generalizante heredado de Aristóteles, Bacon exhorta a la utilización de un método inductivo y experimental que encauzará el buen conocimiento de la naturaleza. Bacon crea este método donde las verdades ya no son las especulaciones racionalistas que derivaban verdades producto de la razón, sino que provienen de los hechos concretos y observables, de la experimentación positiva (2006).
}

En lugar de verdades más allá de lo palpable, Bacon propone el análisis de lo concreto para partir de ahí a lo general. La novela policial (y la ciencia moderna) comulga con esta propuesta inductiva; como bien explica también Morales:

las formas de construir el conocimiento en la filosofía de Bacon tienen una afinidad con los métodos de investigación del detective en el género policial, ya que el empirismo se funda en la observación de los hechos manifiestos, en ese sentido es factual, y avanza en su conocimiento a través del método de la inducción (2006). 
A partir de los testimonios recopilados y de su propia investigación documental, el Bacon novelístico trata de reconstruir el panorama de la comunidad científica nazi durante la guerra en pro de revelar la identidad de Klingsor. Su método es, en efecto, inductivo. Sin embargo, existen varias diferencias con el género policial: el crimen a investigar no es específico, sino que se diluye entre todos los posibles crímenes atribuibles a la ciencia nazi; Bacon no es un detective, sino un militar; por último, y acaso lo más importante, el misterio no es resuelto: la identidad de Klingsor nunca se confirma, a pesar de las sospechas que se puedan albergar sobre algunos de los personajes.

A pesar de las diferencias enumeradas, existe una clara inclinación al género policial y sus intrigas, así como a escenas (sobre todo eróticas) propias de la novela negra, suerte de evolución que el género experimentó en Estados Unidos a mediados del siglo XX. Las coincidencias con dicho género no son casuales pues, como concluye Morales en su artículo:

La aventura de la verdad es pertinente tanto al género [policial] como a la ciencia. El motivo de la verdad en la novela tiene una doble dimensión, o más bien, dos campos: existe una verdad en la ciencia, que los nuevos descubrimientos la han hecho cada vez más esquiva, incluso inaprensible; y por otro lado una verdad en la investigación acerca de la identidad de Klingsor, también inalcanzable (2006).

Bacon, enamorado de Inge (verdadero nombre de Irene, quien resulta ser una agente rusa), termina por entregar a Links quien, según los rusos, es Klingsor. Ella le expone su visión de los hechos, ante lo que Bacon contesta "tu historia es coherente, pero ello no quiere decir que sea cierta (...) Se trata de una interpretación de los hechos, pero puede haber otras..." (p. 435).

Irene ha resuelto el enigma inductivamente, tal como los detectives de las novelas policiales, pero esta resolución no lleva a la verdad. Al menos, Bacon ya no lo cree así. No importa que el proceso se siguiera a la perfección, que el resultado se pudiera exponer lingüísticamente con toda coherencia, nada comprueba fehacientemente que Links sea Klingsor. No obstante, Bacon acepta, lo entrega, asume esa versión de los hechos que no necesariamente es verdadera pero que podría serlo, trayéndose abajo trescientos años de raciocinio cuya aplicación, ya no queda duda, puede llevar al equívoco.

Como un electrón cuya ubicación es indeterminable, así mismo se escurre la verdad entre los dedos de quiénes quieren apresarla, porque lo que queda son versiones de los hechos; los hechos en sí ocurrieron y se perdieron para siempre 
en el tiempo. No es casual entonces que la novela se pueda enmarcar en el género policial, género "heredero del iluminismo" (Morales, 2006): ¿qué mejor manera de echar por tierra la fe ciega en la razón que con una novela policial cuyo enigma motor nunca es resuelto? $Y$ si esa novela tiene por marco la comunidad científica de mediados del siglo $X X$, recién sacudida por los postulados de la física cuántica que acabaron con las seguridades newtonianas, mejor todavía. Reflexiona Morales:

El relato de Links tiene la finalidad de dar cuenta de su siglo, expresar una memoria histórica que no margina a la denuncia. El marco histórico es el que hace hablar acerca de estas reflexiones sobre la función de la razón y su aparente decadencia como elemento emancipador del ser humano (2006).

Bacon traicionó a su colega investigador por el amor de una mujer. Links se encarga de escribir la historia, y cerca del final se pregunta "¿Bastará decir, para perdonarlo, que yo hubiese hecho lo mismo?" (p. 440). Las pasiones, no la razón, determinan los destinos de los personajes principales, muy a pesar de que los dos sean científicos.

\section{Conclusiones}

La narración de En busca de Klingsor realiza un procedimiento poco común al poner en tela de duda la verosimilitud del relato, pues muestra la falibilidad de su narrador. Más que generar un problema o una incoherencia, el texto juega con el hecho y lo convierte en un recurso para criticar la pretendida objetividad no de la ciencia, sino de cualquier tipo de discurso. En palabras del propio narrador,

\footnotetext{
Debemos desterrar esa maldita tentación teológica que tienen los críticos literariosy científicos, por cierto-, según la cual los textos son como versiones actualizadas de la Biblia. Ni un autor se parece a Dios -yo puedo asegurarlo-, ni una página es una mala imitación del Arca de la Alianza o de los Evangelios. Y, por supuesto, los hombrecillos que aparecen bosquejados con tinta tampoco son criaturas similares a nosotros. Nuestro gusto por las metáforas puede meternos en grandes aprietos (pp. 25-26).
}

La literatura, mejor dicho, la escritura, rehace la realidad, no es capaz de sustituirla o dar cuenta fehaciente de ella. Pero si desde el principio del relato Links se preocupa por afirmarlo, ¿por qué se cura en salud con la explicación del título "Hipótesis"? Si él mismo sabe que no hace más que jugar con "hombrecillos que aparecen bosquejados con tinta", ¿hacía falta semejante 
confesión? Tratándose de un hombre moderno y, para más señas, matemático, claro que hacía falta, es su último intento de creer en su capacidad para dar cuenta de lo que sabe, motivación medular de todo ser en busca del conocimiento. Aceptar a pies juntillas que semejante transmisión no es posible, al menos no como lo imaginaron los iluministas del siglo XVIII, es reconocer la inviabilidad del mundo como lo conocemos, por lo que la resignación es parcial. Sí, es vano, pero no queda otra salida. Relatar es posible únicamente como creación literaria. La transmisión objetiva de conocimientos o acontecimientos es un relato imposible.

La novela de Volpi es entonces una gran metáfora, de esas que Links dice que pueden meternos en aprietos, sobre esa búsqueda incesante por la verdad, por el conocimiento absoluto que se escabulle cuando más cerca se cree tenerlo. Una reflexión crítica de los presupuestos de la modernidad y la fe en la razón, no solo de los científicos, sino también de los literatos y la humanidad toda, aunque muy particularmente de los primeros pues, como reza el epígrafe de la novela, "La ciencia es un juego, pero un juego con la realidad, un juego con los cuchillos afilados" (p. 9). El discurso científico no escapa de la ficcionalidad atribuida a todo discurso, pero su caso es aún más crítico pues la ciencia pretende dar cuenta de lo cierto, de lo que determinará la visión de mundo de la época con todo lo que esta implica, como leyes, normas de convivencia y avances tecnológicos, médicos y logísticos. No deja de ser un juego, un manejo de lenguaje, pero mucho más peligroso que los demás en cuanto es más susceptible de ser creído y aplicado. 


\section{BIBLIOGRAFÍA}

Depetris, C. (2006). Del testimonio científico a la narración literaria: el diario de expedición de Luis de la Cruz. Latinoamérica: Revista de Estudios Latinoamericanos, 107-129.

Mackenbach, W. (2005). La historia como pretexto de la literatura. La nueva novela histórica en Centroamérica. K. Kohut, \& W. Mackenbach, Literaturas centroamericanas hoy. Desde la dolorosa cintura de América. Madrid: Aey.

Morales, F. (2006). La crítica de la Razón y la Modernidad desde el género policial. Espéculo.

Spang, K. (1984). Mímesis, ficción y verosimilitud en la creación literaria. Anuario filosófico, 153-159.

Villanueva, D. (1989). Comentario de textos narrativos: la novela. Gijón: Júcar. Volpi, J. (1999). En busca de Klingsor. Bogotá: Seix Barral. 
Revista Herencia, Vol. 31 (1), enero-junio, 2018. 